\title{
Update on Ifremer technological developments and operational feedbacks with underwater systems
}

\author{
V. Rigaud \\ Ifremer \\ Zone Portuaire de Brégaillon \\ 83507 La Seyne sur Mer France \\ vincent.rigaud@ifremer.fr
}

\begin{abstract}
This paper reports on the status of Ifremer Underwater systems. It will focus on recent innovations, improvements and operational references of the remotely operated vehicle "Victor 6000", of the autonomous underwater vehicles "Aster $X$ " and "Idef $X$ ", of the new "Sysif" seismic tool and some hints about RanD in the domain of Advanced Intervention AUVs.
\end{abstract}

\section{INTRODUCTION- FROM MANNED SUBMERSIBLE TO AUTONOMOUS SYSTEMS}

Ifremer has been engaged in the development of underwater technologies since the beginning of the 1970s and in the operational use of underwater systems within the European oceanographic fleets. Development of the deep sea ROV Victor 6000 and a complete upgrade of the well-known manned submersible Nautile in 2000-2002 are some of the major activities undertaken recently by Ifremer, as well as numerous reference in the field of autonomous underwater vehicle for survey tasks but also for RandD on complex autonomous telemanipulation tasks.

Manned submersibles have been pioneers in the field of operational access to the deep sea for science for 20 years. Along with the Shinkai 6500 from Jamtec in Japan and with the two MIR vehicles from Russsia, Ifremer's Nautile is capable of diving up to a depth of $6000 \mathrm{~m}$. It was overhauled in 2000-2002 and is currently available for science investigations with more than 1600 operational dives already conducted.

Nautile (Figure 1) is mainly dedicated to oceanographic investigation but has also been used for archaeology ( Titanic cruises) and on oil spill reduction, for example on the wreck of the Prestige off the coast of Galicia. Nautile is a very flexible tool for exploration of complex unknown underwater environments..

On the other side of the technological panel numerous projects have been conducted recently with European partners for offshore applications. This effort started with the development of the supervised AUV Sirene [4] that was designed for accurate launch and deployment of a benthic station. The prototype was built by Ifremer for depths up to $4000 \mathrm{~m}$ and has demonstrated progress in precise autonomous positioning and tracking using Kalman filter techniques, robust acoustic range-estimators, chirp communication and noise reduction technologies, as well as electro-acoustic-compatibility.

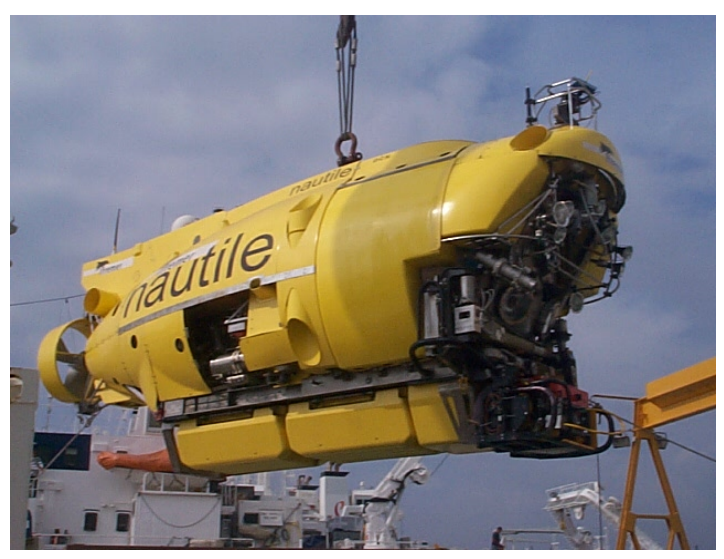

Figure 1. Nautile Manned Submersible ㄷ Ifremer

Then technology developed in Sirene was applied to the Swimmer research and development project in collaboration with Cybernetix for the offshore industry [1] (Cf. Figure 2).

This hybrid AUV, carries a classical ROV and was designed to dock on a preinstalled bottom-station linked by a permanent umbilical to the surface. Once docked, the Swimmer "Shuttle AUV" deploys the ROV using the established link with the surface, through the permanent field umbilical. Over and above the spin-off of Sirene technologies, the autonomous docking concept was demonstrated using an innovative, integrated high precision positioning system (Figure 2).

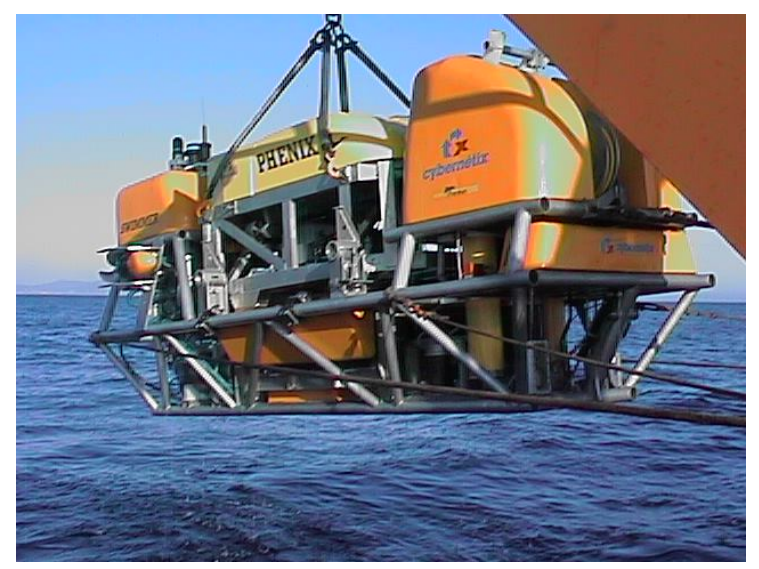


Figure 2. Swimmer Hybrid AUV (C) Ifremer

The successful development of Swimmer was followed by an ambitious prototype AUV that was built in collaboration with Cybernetix, Hitec-Horten, and Herriot Watt University. This is the Alive intervention AUV (Figure 3), the first AUV equipped with manipulators. The vehicle is able to dock with grabbers on a typical offshore ROV panel in an acoustically supervised mode. This project demonstrated innovative robust optical and acoustical dynamic positioning and sensor based docking, proven at sea in real conditions [3].

Beyond these technological advances, the need for a more classical survey AUV has arisen within Ifremer scientific programs, mainly dedicated to environmental survey, in the field of physics, chemical analysis, living resources survey, or risk assessments for geophysics (slope instabilities and seismic surveys). The key words Then were "optimise the cost of data collection". This has led to the establishment of an operational program based on a fleet of coastal survey AUVs.

With respect to the ROV Victor 6000, the system has been in operation since 1997 and has been intensively used for multi-disciplinary science cruises all over the world. The vehicle is in permanent evolution. A new high resolution mapping module has been designed. This scientific tool skid is dedicated to "optical and acoustical mapping" at limited altitude for very high resolution "multi-modal" mapping. In 2009 the system will be fully overhauled after 10 years of continuous operations.

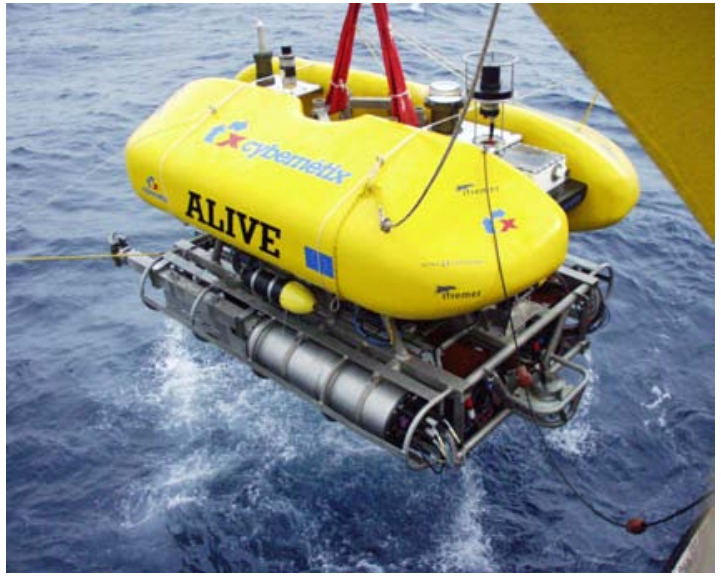

Figure 3. A/ive Intervention AUV. Automatic docking by video and sonar control CIfremer

\section{VICTOR 6000, REMOTELY OPERATED VEHICLE}

Victor 6000 is a scientific electrical ROV entirely dedicated to deep sea scientific studies. Victor 6000 has achieved numerous oceanographic cruises in the Atlantic, Mediterranean , Arctic and Pacific oceans. More than 370 dives have been carried out from L'Atalante, Thalassa,
Pourquoi pas? Sarmiento De Gamboa (CSIC-Spain) and Polarstern (AWI-Germany) research vessels. Victor 6000 (see Figure 4). The vehicle is part of a global system built of subsystems, "scientific modules" (tool sleds), winch and cable, dead weight and umbilical, positioning subsystem using acoustic ultra short base line (USBL) techniques, and all software for data and dive management.

The vehicle itself includes specialised servicing equipments dedicated to propulsion, video surveying, lighting, remote control, navigation and telemanipulation. The positioning is carried out by an ultra short baseline "POSIDONIA" $®$.

The toolsleds or modules composed of a frame located under the vehicle where most of the scientific instruments are installed.

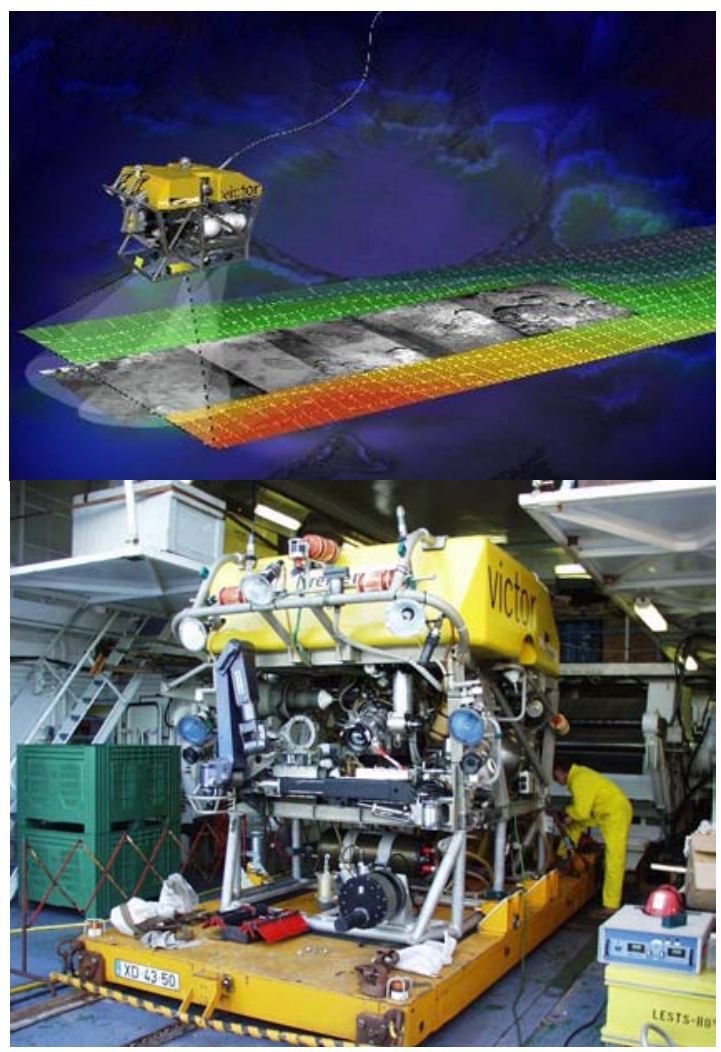

Figure 4: Victor 6000 Deep sea ROV with High resolution Optical and acoustical mapping MMR CIfremer

Since 10 years, Victor 6000 is proposed to scientists with a "basic sampling" toolsled, which includes a retractable drawer, sampling tools and temperature probes. Since 2 Years Victor 6000 is proposed with a second innovative toolskid dedicated to high resolution mapping of the sea bottom, with acoustical and optical devices.

The new survey module has been designed to increase the ability of the vehicle to explore and work on larger areas ( $\mathrm{km}$ scales). This new module, also called "Module de Mesures en Route” (MMR), [8] complements oceanographic vessels for 
high resolution bathymetric mapping, and long range optical mosaics. It can cover surfaces of up to $1,5 \mathrm{~km}^{2}$ per day. It is fitted with multi-beam sonar (Reson 7125), long range- high dynamic vertical camera with adhoc flashs, sub bottom profiler or mono-beam sounder (EK60 Simrad) for gas detection.

For optical mosaics at high altitude (Optical observation from $8 \mathrm{~m}$ to $12 \mathrm{~m}$ ), a new generation of black and white still camera associated with flashes (1200 joules) is available on the MMR. In real time, the scientist could have a large view of each picture of the bottom . In post processing mosaics can be done. This new long range High dynamic camera built by Ifremer is named OTUS and can deliver $100 \mathrm{~m} 2$ image at 10 meter altitude for photo mosaics using the MATISSE ${ }^{\circledR}$ optical mosaic software

The innovative camera OTUS is based on Still camera with a CCD THOMSON MPP, with CDD cooling by Pelletier effect. Its a $1 \mathrm{M}$ pixel with large pixels $19 x 19$ um to catch light. OTUS, associated with four 300 Joules flashes, delivered 1 image x 5 seconds, and is link to surface by 10/100Mb Ethernet. Pictures are tiff 2Mbits pixel on 14 bits.

A deep record dive at high latitude (79deg north) was reached in the Molloy Deep at $5550 \mathrm{~m}$. The operations since 2000, represent $5500 \mathrm{~h}$ of work/ survey near the seafloor The system have contributed significantly to the observation and the monitoring of the deep benthic ecosystems in various environments of the mid-oceanic ridges and the continental margins.

As an illustration of a reference campaign we will use (amongst others!), the MoMARETO cruise [9] which took place on three hydrothermal fields of the mid-Atlantic ridge. The main objective of the cruise was to study the spatial and temporal dynamics of hydrothermal communities colonizing the MoMAR area. Most of the dives were centred on Lucky Strike, two other vent fields, Menez Gwen and Rainbow, were also visited.

On Lucky Stricke the challenge was the high-quality bathymetric mapping on chaotic and rough terrain with active hydrothermal edifices, fields of pillow lava, typical lava lake structures, fissures and cracks. After several mapping from 90 to 30 meters altitude survey, a reference dive at $8 \mathrm{~m}$ altitude have been conducted to couple the micro-bathymetric survey with OTUS mosaics.

The data acquired give important insights on bottom texture and structure and permitted mapping of vent faunal habitats in the vicinity of active sites. A complete coverage of the Tour Eiffel edifice was done $(80 \mathrm{~m} \times 120 \mathrm{~m})$. The survey around this 10 -m high structure was particularly tedious and several additional passages were needed to complete the data set. A first image mosaic mapped the distribution of faunal assemblages around the structure. This small-scale survey took 4 hours of bottom time (Figures 5,6).

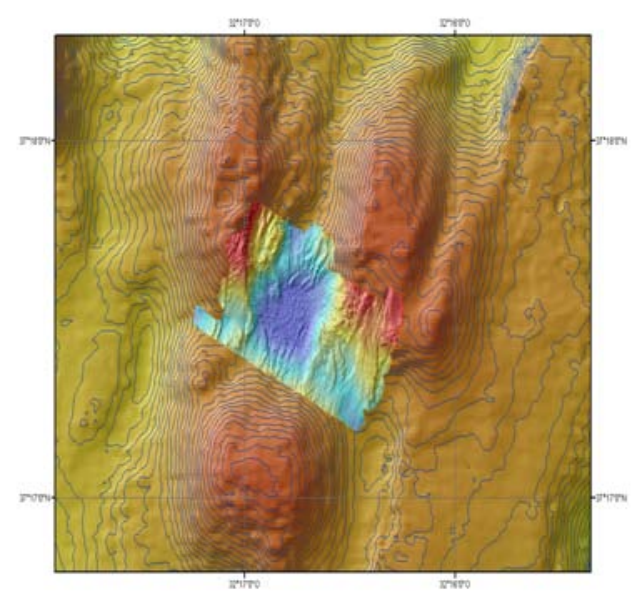

Figure 5: The center of the map is occupied by a MMR "Reson Multibeam sonar 7125 " map. The area covered is $1000 \mathrm{~m}$ x $500 \mathrm{~m}$ for a resolution of $1 \mathrm{~m}$. The lava lake is visible in blue and is surrounded by several active hydrothermal structures. In contrast, the background shows the previous upto-date map of the area, obtained from the ship. The area covered was $4000 \mathrm{~m}$ $\mathrm{x} 4000 \mathrm{~m}$ for a resolution of $50 \mathrm{~m}$. (c) Ifremer

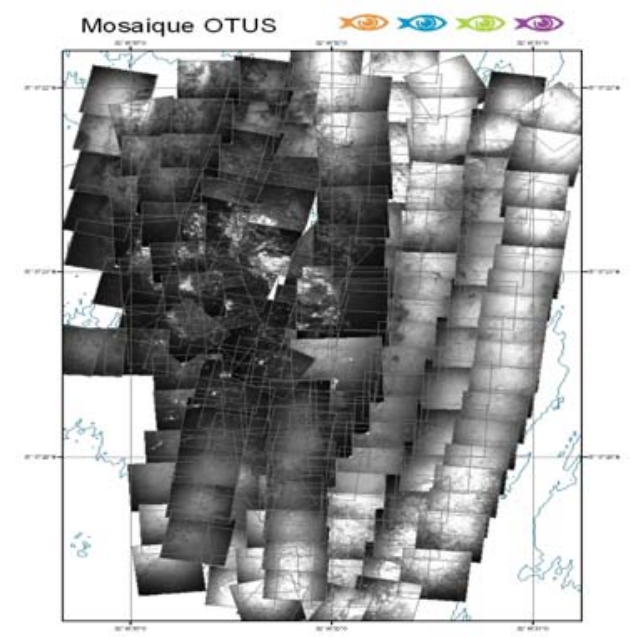

Figure 6: Raw mosaic of black and white OTUS images giving an optical view of Tour Eiffel hydrothermal vent . (c) Ifremer

A fish and gas detection payload composed of two fishery echo-sounders $(70 \mathrm{kHz}$ and $200 \mathrm{kHz})$ was installed during the 2006 "Bionil" cruise off the Nil Fan in the Mediterranean sea, on board the R/V Meteor with German (MPI, Bremen University) and French scientists. Fishery echo-sounders permit to detect gas plumes because it gives the intensity of each echo in the water column under its transducer. As gas has a good acoustic reflectivity, it seems easy to detect plumes near the seafloor either with ROV or AUV (Figure 11). . The EK60 suite is shared as numerous sensors between AUVs and ROV. 


\section{SYSIF NEW DEEP SEA TOWED SEISMIC SYSTEM}

Ifremer has also recently developed a new deep-towed seismic system designed for High to Very High resolution near-bottom marine seismic surveys. This new tool named SYSIF is dedicated to the study of deepwater geological objects especially geo-hazards (Figure 7). The innovation remain in the design of a new seismic source based on JanusHelmotz acoustic source made of a piezoelectric ceramic stack inserted between two similar head masses. This source can be tow near the bottom up to 3000m depth.

The use of classical seismic sources from the surface (air gun...) is incompatible with a good lateral resolution which is driven by the width of the first Fresnel zone, linked to the distance between the emitter and the target altitude. The coupling of a mechanical resonance and a fluid resonance allows a large frequency bandwidth and offers a highly repeatable acoustic signal perfectly tailored for accurate soil characterization (Figure 8).

This new equipment is highly innovative and provides, in very deep sea. It is composed of a seismic depressor towed by the ROV Victor Electrical/Optical cable, with a seismic streamer behind.

The system includes 2 seismic sources:

- THR (650-2000Hz) vertical resolution: 0.6m

- $\quad$ THR (250-1000Hz) vertical resolution: $1 \mathrm{~m}$

And 2 streamers

- One bi-channels

- $\quad$ One multi-channels in development

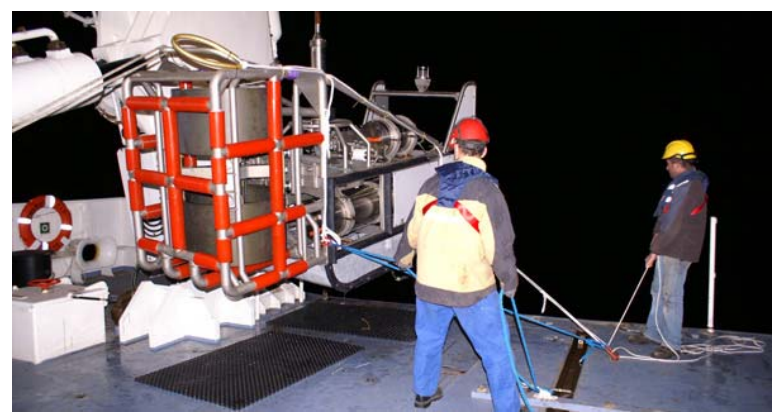

Figure 7: Sysif Deep Tow Sismic sources

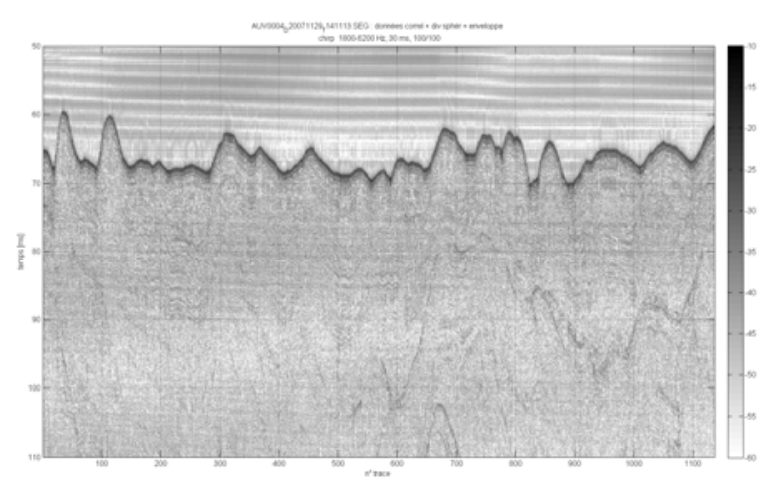

Figure 8: Seismic profile image with Sysif CIfremer

\section{AUVS: ASTER ${ }^{\mathrm{X}}$ AND IDEF $^{\mathrm{X}}$}

The various fields of physical oceanography, marine geological resources, fish stock evaluation, natural risks assessments, etc., in the continental shelf and margin regions, all linked to socio-economic demands, are fuelling the need for more detailed, and recurrent surveys. Those needs led Ifremer in 2002 to launch an AUV program to apply autonomous vehicles to operational scientific survey.

The analysis of scientific requirements, led to the specification of a $800 \mathrm{~kg}, 3000 \mathrm{~m}$ depth-rated, modular vehicle with more than $100 \mathrm{~km}$ range capabilities and around $200 \mathrm{~kg}$ payload capacity. For coastal applications this vehicle is operated by a limited crew (3) from small $(<30 \mathrm{~m})$ non specialized boats $\backslash$ or vessels of opportunity. The objective of this program is to establish an operational fleet able to quickly mobilize for environmental survey, for example on nonforecasted events (meteorological events, seismic activity, accidental pollution, etc.). Another goal of the AUV program is to combine AUVs with ROV operations on a classical cruise.

The two sisters AUVs named Aster ${ }^{X}$ and Idef ${ }^{X}$ are 4.5 meters in length with a diameter of 0.69 meters. The AUVs are capable of carrying various payloads in their payload sections for a wide spectrum of applications[2][5].

Typical payloads have been design for :

- Current profiling and physical-chemical parameter measurement

- Sonar imaging for fish-stock evaluation

- Bathymetric sonar, sub-bottom sounder and sidescan sea-bed investigation

Figure 9 illustrates the vehicle general arrangement 


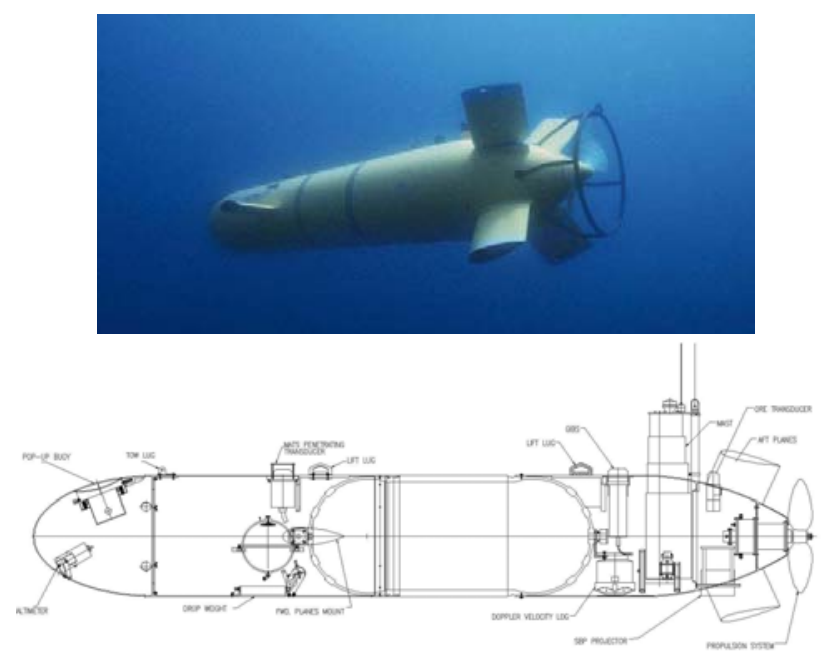

Figure 9 AUVs CIfremer

The use of such an AUV in coastal areas dictates rules for usage, and an evaluation of operational risks. This has led to select a basic operational scenario, in which the vehicle will surface only if an escort vessel is able to manage the security on the sea-surface. In other cases the vehicle will not be permitted to surface without acoustic contact with the escort vessel and will remain underwater, or ultimately lie on the bottom and wait for the escort vessel to command it to surface. For this reason, sophisticated acoustic communication and relocation functions have been included.

From February 04 to January 2009 Aster $^{X}$ and Idef $^{X}$ have been used for 270 Days at sea on 35 campaigns [7]:

- Max depth reached 2500m

- Max distance in one dive $74 \mathrm{~km}$ with one surfacing

- Mean Operational team 2 or 3 people

- Mobilization from 10 different vessels.

The Figure 10 shows an underwater high resolution map (Multi-Beam sonar EM2000), built and overlaid on another original map built from the ship hull mounted sonar (Simrad EM300). This $(1 * 1 \mathrm{~m}$ square pixels) map is built with the Aster ${ }^{X}$ cruising at 3 knots over the terrain at 60 meters altitude from the bottom in a very rough terrain, from $300 \mathrm{~m}$ depth to 1000 depth. The followed trajectory crossed the lines perpendicularly, climbing with a pitch in order to keep the vehicle axis parallel to the mean slope and descending at constant attitude. Here, the cost of mapping has been optimised, in terms of time of survey (18kms in line $4 \mathrm{~km} 2$ covered in less than 3 hours, First level map built on the ship 30minutes after the end of the dive). This result is an illustration of the data cost optimisation, by minimization of the needed ship time versus the survey time.

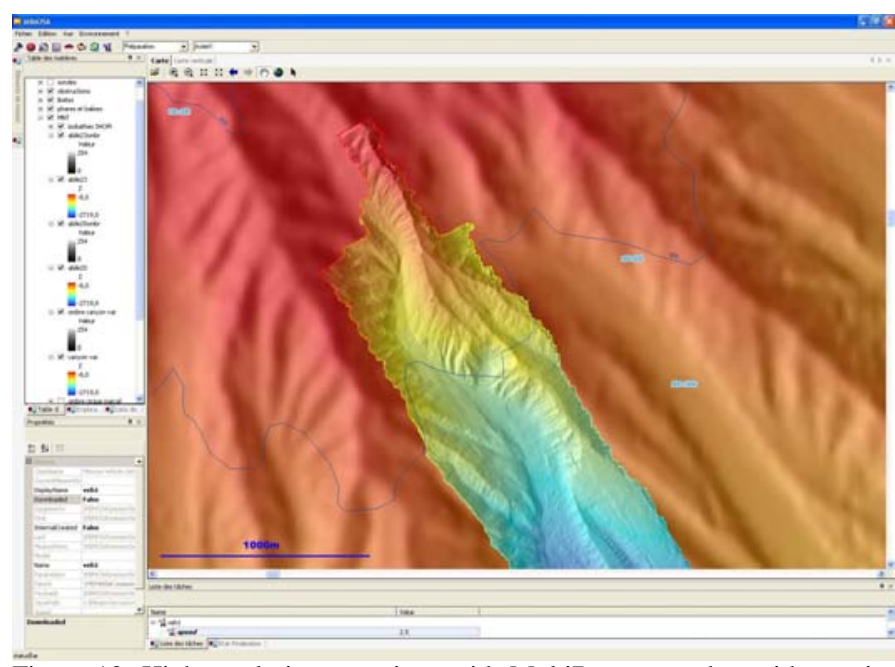

Figure 10: High resolution mapping with MultiBeam sounder, with terrain following function in the Var Canyon from 300 to $1000 \mathrm{~m}$ depth, crossing the levels lines perpendicularly (C) CNRS-INSU-Géosciences Azur-Ifremer.

During this cruise the Aster ${ }^{X}$ AUV demonstrated new capabilities. It travelled for $138,880 \mathrm{~m}$ in approximately 41 hours over 6 separate dives, mapping several mud volcanoes and small pop marks with the EM2000 multi-beam, indicating gas sweeps activities. It was the first time an AUV fitted with a fishery echo-sounder was used to detect gas. (Fig 11 with Victor 6000 Scientific results of this campaign are not yet published and cannot be referenced or shown in this paper)

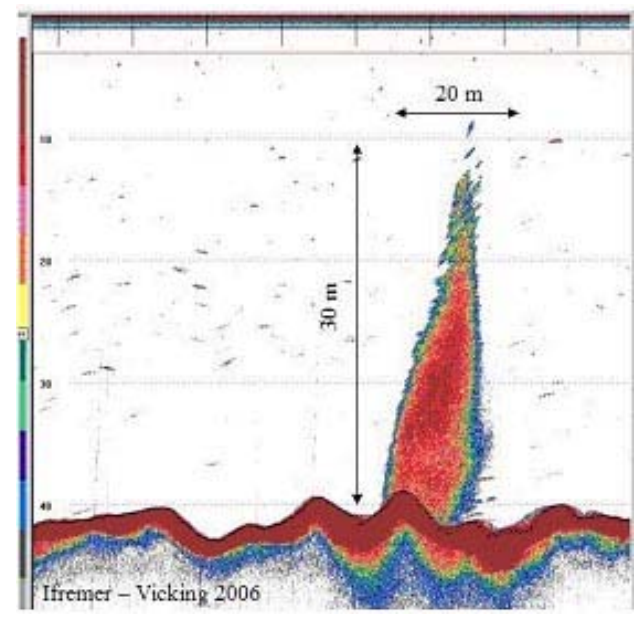

Figure 11. : Gas detection using EK 60 fishery echo-sounder - 70kHz installed onboard ROV Victor6000 during Vicking Cruise of R/V Pourquoi Pas in 2006). The altitude of the echo-sounder above seafloor is $40 \mathrm{~m}$. (Courtesy of Hervé Nouzé, chief Scientist of Vicking Cruise). (C) Ifremer 


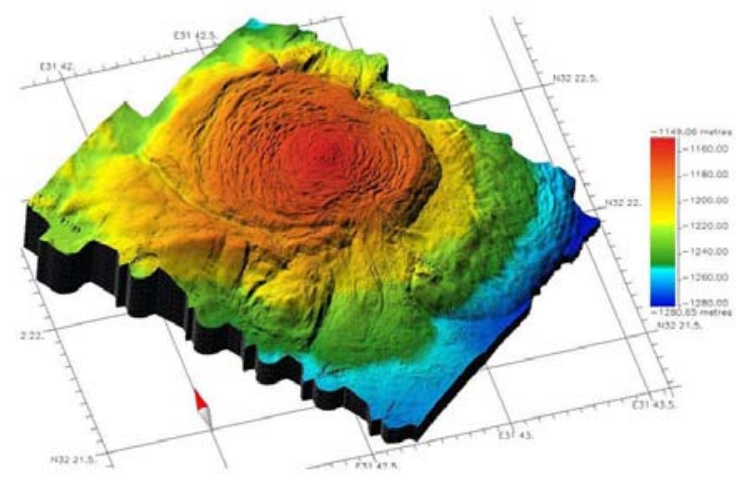

Figure 12: Ultra-high resolution $(<50 \mathrm{~cm})$ microbathymetry of Amon mud volcano, in the Nile collected using AUV Aster ${ }^{x}$ (see Doc. $N^{\circ} 2$ ) during the BIONIL Cruise (Chief Scientist Antje Boetius), Mediflux Project, Euromargins Programme. 3D image processed and kindly provided by Georges Buffet, Geosciences Azur. (C) CNRS-INSU-Géosciences AzurIfremer.

Recently a new acoustic sub bottom profiler has been developed for offshore business survey, and also for high resolution mapping of the first meters of sediment layers. The Echoes 10000 AUV echo-sounder is a co-development from iXSEA with Ifremer, it operates in a frequency band from 1.5 to $6 \mathrm{kHz}$. The Fig 13 shows some results with this new innovative device. This sensor is also shared with Victor 6000 .

Considering ongoing new developments, a new autonomous safe launch and recovery system named Caliste (Fig 14-a) have been design and is now used in operations.

A new technological project related to evaluation of an $\mathrm{H} 2 / \mathrm{O} 21.6 \mathrm{~kW}(36 \mathrm{kWh})$ compact fuel cell designed by Helion corp. and integrated by Ifremer is underway with an objective to achieved in October 2009 a dive of more than $350 \mathrm{~km}$ from Marseilles to (in direction of) Barcelona! (Fig 14.b).

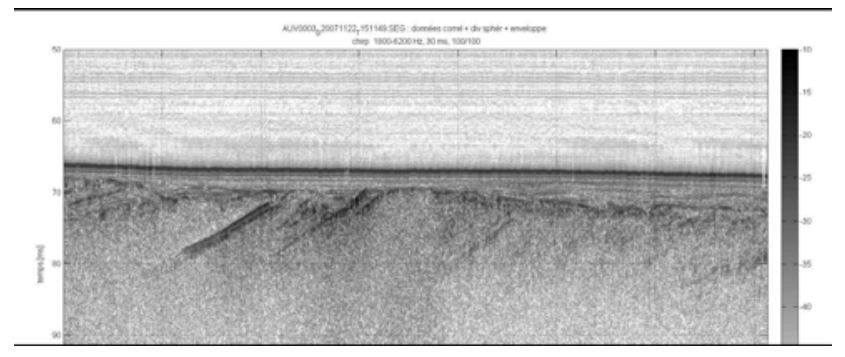

Figure 13: Sub bottom profiling by AUV @ Ifremer
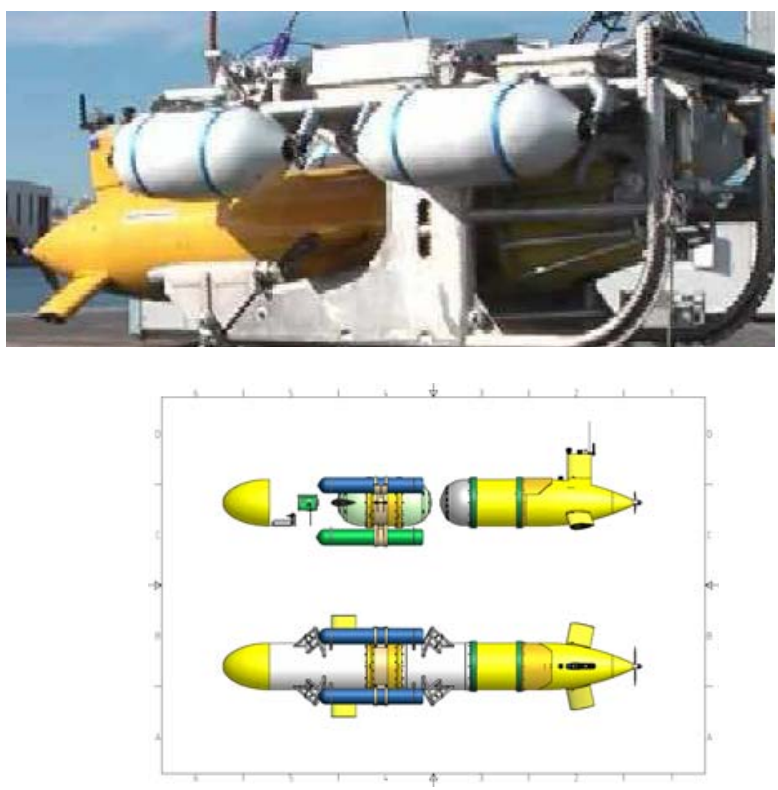

Figure 14: New systems: a/ New LARS Caliste andb/ Fuel Cell powered version of $A U V$

\section{CONCLUSIONS}

We are now on operational phase for AUVs uses. Developments are ongoing and yield higher levels of autonomy and behavioural robustness at sea. For example, high level programming mission preparation systems, named Mimosa ${ }^{\circledR}$ and PSE ${ }^{\circledR}$, are being improved for mission building and high level, fault tolerant control. To support scientific needs new payload developments are also underway, taking into account the required instrumental modularity on the system, e.g., new Chirp Sediment Sounder, ln situ Spectrometer. In addition, the scientific requests to use AUVs are still significant (220 days at sea requested for 2009).

With operational ROV, data fusion of acoustical and optical maps based on concurrent mapping localization techniques with data fusion technologies is underway. This is still an open research activity in terms of signal processing and considering the development of new sensors and subsystems. Other research activities based on 3D optical reconstruction with non calibrated stereo are also conducted, with a first demonstration of a stereo head installed on the Victor 6000 manipulators for a cruise on the Atlantic ridge during the 2006 summer to map hydrothermal vents and cold corals [6]. In 2009 Victor6000 will be fully overhauled. The control system, the surface shelter, new umbilical and update of old fashioned systems would improved the efficiency of the system and optimised the possession cost of the vehicle trough sharing of payloads and software with AUVs. New scenario of concurrent dives with AUVs and ROV would also arise in the future campaigns .

In cooperation with a consortium leaded by Acsa Company, with CNRS Labs (LOV and LMGEM), ACRI IN and ST 
companies and ISITV engineering school, We are also building a new generation of wingless gliders named SeaExplorer with underwater communication and positioning capacities [10].

In parallel, permanent RandD on heterogeneous systems (AUVs/ships/ autonomous surface systems/underwater observatories) and on autonomy in all the components (energy, positioning, navigation, control) are conducted with regular benchmarking and integration of mature components on operational underwater systems, with a permanent feedback from operations at sea.

\section{REFERENCES}

[1]-Chardard, Y, V (1998, October). SWIMMER, French group developing production umbilical AUV, Offshore Magazine, pp. 66-67.

[2]-Ferguson, J. (2000). Explorer - A modular AUV for commercial site surve. In Proc. Underwater Technology 2000 conference, Tokyo, Japan, May 23-26.

[3] - Perrier, M., \& Brignone, L. (2004, May). Optical stabilisation of the AUVE AUV ln Proc. 14th International Offshore and Polar Engineering Conference, ISOPE 2004, vol. 2, pp. 233-238, Toulon, France.

[4]- Rigaud, V, Semac, D., Drogou, M., Opderbecke, J., \& Marfia, C (1999, May). From SIRENE to SWIMMERsupervised unmanned vehicles: operational feedback from science to industry. In Proc. ISOPE'99 International Conference, Brest, France.
[5] Rigaud, V, Michel, J.L., Ferguson, J.s., Laframboise, J.M., Crees, T., Leon, P., Opderbecke, J., \& Chardard, Y. (2004, May). First steps in Ifremer's autonomous underwater vehicle program-A $3000 \mathrm{~m}$ depth operational survey AUV for environmental monitoring. Ln Proc. 14th International Offshore and Polar Engineering Conference, ISOPE 2004, vol. 2, pp. 203 208, Toulon,France.

[6]- Sarradin, F.M., Sarrazin, J., Cadiou, J.E, Olu, K., Desbruyères, D., Rigaud, V, Drogou, J.E, Lecornu, E, Rolin, J.E, Vuillemin, R, CambonBonavita, M.A, Sauter, K, von Juterzenka, K., Boetius, A., Serrao Santos, R, Colaço, A, Pasco al, A, Oliveira, P., Shillito, B., Zal, E, Schultz, A, Taylor, F., Lane, D., Loke, RE., du But, H., Waldmann, C, Cormack, A, Sanfilippo, L., \& Masson, M. (2004, May). Extreme ecosystem studies in the deep ocean: technological developments (EXOCETD). In Proc. 14th International Offshore and Polar, Engineering Conference, ISOPE 2004, vol. 2, pp. 738745, Toulon, France.

[7] J. Opderbecke, JM. Laframboise, OCEANS'07 : 'AUVs for oceanographic science at IFREMER, project progress and operational feedback» 18-21 June (2007) OCEANS'07 IEEE Aberdeen Conf. Proceedings (IEEE), 2007/06

[8] Simeoni P., Sarrazin J., Nouze H., Sarradin PM., Scalabrin C., Siuquin JM., OVEANS'07, “Victor 6000: New High Resolution Tools for Deep Sea Research. "Module de Mesures en Route » 18-21 June (2007) OCEANS'07 IEEE Aberdeen Conf. Proceedings (IEEE), 2007/06

[9] Sarrazin J. , Sarradin PM, Christophe ., Buffier E.,Clodic G., Desbruyeres D., Fouquet Y., Le fur Y,n Le Rest J, Lecornu F., Guillement P., Lux S " real-time dive on active hydrothermal vents OCEANS'07 IEEE Aberdeen Conf. Proceedings (IEEE), 2007/06, Pages 1-4

[10] www.seaexplorer.fr 